\title{
Correspondence
}

\section{Medvedev's Complaint}

SIR,---I have just read the letter by Dr J. J. Bikerman "Medvedev's Complaint" (Nature, 228, 297; 1970), which I fail to understand. Either he misread my paper (Nature, 227, 1197; 1970) or he misunderstood the real situation with the Ciba Foundation's tenth annual lecturo on ageing research, which was very different from Dr J. J. Bikerman's position over his lecture in France. When Dr Bikerman was invited to give a lecture in France the first thing he did was to apply to the National Science Foundation for travel funds. He did not appeal for permission to visit France or apply for a visa. Dr Bikerman did not explain why his application for money was turned down but he is cortainly right to suggest that the US National Science Foundation had the authority to decide about proper distribution of travel funds, which are not limitless even in the USA.

The funds for my travel for the tenth annual lecture of the Ciba Foundation were available and would have been provided by the director of the Ciba Foundation, Dr G. E. W. Wolstenholme: this is clear from his official letter published in my article (p. 1198). The invited lecturer asked for no money for this trip, but only for permission and a visa. In Dr Bikerman's case the problem was the money, whereas in the other caso the problem was one of human rights and those of a scientist. 'This is what justified the enormous efforts on the part of Ciba Foundation and of the lecturer-offorts which unfortunately failed.

Dr Bikerman will probably understand this difference even better when he knows that the issue of Nature containing his letter-published on October 17, 1970-has reached libraries here safely. The issue of Nature containing the paper we are discussing, which was published on September 19, 1970, has not yet reached oither libraries or individual subscribers here, and nobody knows when it will arrive. My colleagues here therefore know only of Dr Bikerman's complaint and not what the discussion is really about, though they have probably gathered an impression from Dr Bikerman's comments that something is perhaps really wrong with my mind.

\section{Yours faithfully,}

\section{Zh, A. Medvedev}

Laboratory of Proteins,

Research Institute of Physiology and

Biochemistry of Farm Animals,

Borovsk,

USSR.

\section{Nomenclature of Immunoglobulins}

SiR,-Immunoglobulin structure and function have been dealt with extensively in a number of excellent review articles in which the matter of nomenclature is clearly defined. Unfortunately, the revicw article on the nomenclature of immunoglobulins by D. S. Rowe (Nature, 228, $509 ; 1970$ ) contains questionable statements and includes a misleading suggestion concerning the functional role of proline residues in the "hinge region".

(1) The InV-factor is not in fact shared by $\lambda_{\text {-chains, but }}$ is associated with the constant sequence regions of $x$-chains ${ }^{1}$, while the constant regions of $\lambda$-chains are carriers only of the $\mathrm{Oz}$-factor ${ }^{2}$.

(2) It is well known that proteolytic digestion of IgG by pepsin gives rise to the $\mathrm{F}\left(a b^{\prime}\right)_{2}$ fragment. However, in contrast to papain, the splitting of the heavy chain does not occur closer to the amino-terminal end of the chain, as stated in the text, but closer to the carboxylterminal end shown, in fact, in Fig. 2 of Dr Rowe's article.

(3) The suggestion that proline residues are responsible for the high flexibility of the hinge region because of their high frequency of occurrence may be misunderstood. Proline, of all amino-acids, gives to the sites where it occurs the least conformational freedom ${ }^{3}$ and a high incidence of it should therefore make a sequence region rigid rather than flexible $e^{4}$. I would like to propose that in the hinge region proline may prevent adjacent soquence regions from globular folding on to ono of the "homology regions" and thus make them more susceptible to protoolytic digestion. A satisfying explanation of the particular conformation of the hinge region must, however, await elucidation of its backbone structure, carried out at a resolution higher than $6 \AA$. X-ray and computational studies to achieve this end are currently in progress in several laboratories.

\section{Yours faithfully,}

\section{H. D. WeISCHER}

Swiss Serum and Vaccino Institute,

Department of Research CH 3018 Berne, Switzerland.

${ }^{1}$ Hilschmann, N., and Craig, L. C., Proc. US Nat. Acad. Sci., 53, 1403 (1965).

2 Appella, E., and Ein, D., Proc. US Nal. Acad. Sci., 57, 1449 (1967).

${ }^{3}$ Mandelkern, L., Biological Macromolecules, 1, 675 (edit. by Fasman, G. D.) (Dekker, New York, 1967).

'Welscher, H. J., Intern. J. Protein Res., 1, 267 (1969).

\section{Dr Rowe replies as follows:}

SrR,-Dr Welscher's first two points are correct. With regard to the third $\Upsilon$ stated generally agreed facts as follows: "That region of the heavy chains close to the site of the action of papain is notably rich in proline residues and evidence derived from electron microscopy suggests that this is the most flexible region of the molecule".

It is an exercise in semantics which $\mathrm{I}$ leave to the reader to decide whether this implies "the suggestion that proline residues are responsible for the flexibility of the hinge region ...". If hypothesis is warranted one might recall that most hinges comprise both rigid and flexible parts, and this seems to be the substance of Dr Welscher's suggestion. The term "hinge region" is perhaps a useful one to describe a particular flexible portion of the molecule, but it cannot fully be substantiated in structural terms until the flexible components thomselves have been defined.

Yours faithfully,

DAvID S. RowF:

WHO International Reference

Centre for Immunoglobulins,

Lausanne, Switzerland. 